\title{
La regulación comunitaria y española del crowdfunding: una perspectiva desde la protección de datos personales(*)
}

\section{POR FRANCISCA RAMÓN FERNÁNDEZ(**)}

\begin{abstract}
Sumario: I. Introducción.- II. El crowdfunding: algunas notas y consideraciones.- III. El reglamento (UE) 2020/1503 relativo a los proveedores europeos de servicios de financiación participativa para empresas.- IV. La ley 5/2015, de 27 de abril, de fomento de la financiación empresarial.- V. La protección de datos personales en el crowdfunding.- VI. Conclusiones.- VII. Bibliografía.
\end{abstract}

Resumen: la regulación de la figura del crowdfunding en la legislación española y comunitaria con la ley 5/2015 y el reglamento (UE) 2020/1503 establece una serie de condiciones en lo que se conoce como financiación participativa empresarial. La necesidad de obtención de fondos y la inversión para obtener un beneficio son los puntos de partida de la normativa. Junto a ello, y teniendo en cuenta las TIC (tecnologías de la información y comunicación) se plantean diversos aspectos referentes a la protección de datos en la actividad del crowdfunding. En el presente trabajo nos proponemos analizar las diversas cuestiones que afectan a la situación legal y jurídica de esta figura cuya normativa es de factura reciente, para aportar soluciones viables.

Palabras claves: crowdfunding - servicios de financiación participativa para empresas -fomento financiación empresarial - protección de datos personales

(*) Trabajo realizado en el marco del Proyecto I+D+i «Retos investigación» del Programa estatal de I+D+i orientado a los Retos de la Sociedad del Ministerio de Ciencia, Innovación y Universidades: RTI2018-097354-B-100 (2019-2022) y del Proyecto de I+D+i Retos de Investigación, MICINN, del Programa Estatal de I+D+i orientada a los retos de la sociedad (PID2019-108710RB-I00, 2020-2022).

(*) Lic. y Dra. en Derecho. Prof. Titular de Derecho Civil, Universitat Politècnica de València, España. http://www.upv.es/ficha-personal/frarafer http://orcid.org/0000-0002-0936-8229 


\section{Community and Spanish regulation of crowdfunding: a perspective from the protection of personal data}

Abstract: the regulation of the figure of crowdfunding in Spanish and Community legislation with Law 5/2015 and Regulation (EU) 2020/1503 establishes a series of conditions in what is known as business participatory financing. The need to raise funds and invest to make a profit are the starting points of the regulation. Along with this, and taking into account ICTs (information and communication technologies), various aspects related to data protection are raised in crowdfunding activity. In this paper, we propose to analyze the various issues that affect the legal and legal situation of this figure whose regulations are recent, in order to provide viable solutions.

Keywords: crowdfunding - participatory financing services for companiespromotion of business financing - protection of personal data - fertilization - affiliation-inheritance

\section{Introducción}

Las distintas formas de financiación a través de la denominada "participación social" y su necesidad de regulación determinan que sea preciso diferenciarlas entre sí. Cuando hablamos de obtener recursos económicos para un proyecto empresarial, podemos referirnos a la figura del mecenas, el patrocinio o el crowdfunding. Este último ha sido objeto de regulación de forma reciente en España, mediante la ley 5/2015, de 27 de abril, de fomento de la financiación empresarial y también en el ámbito europeo, tras el reglamento (UE) 2020/1503 del Parlamento Europeo y del Consejo de 7 de octubre de 2020 relativo a los proveedores europeos de servicios de financiación participativa para empresas.

En el presente trabajo nos proponemos realizar un análisis detallado de esta reciente regulación, marcando los principales aspectos que denotan la figura jurídica del crowdfunding, para adentrarnos en las cuestiones relativas a la protección de datos personales que puedan afectarle y resolver las mismas de acuerdo con la legislación y la doctrina que se ha manifestado al respecto.

\section{El crowdfunding: algunas notas y consideraciones}

El mundo empresarial y del emprendedor siempre ha necesitado fuentes para ser financiado. La búsqueda de fondos para el desarrollo de proyectos ha sido una constante en dicho ámbito, pero, sobre todo, en el campo de la cultura, especialmente en el caso del patrimonio cultural (Equipo Hispania Nostra, 2018) y del audiovisual (Ruiz, 2010, p. 30; Roig, Sánchez y Leibovitz, 2012, p. 25; González y Palomo, 2014, p. 105). Por ejemplo, en el caso de los museos (Aniorte, 2013). Se habla de mecenazgo, patrocinio y crowdfunding como si fueran figuras sinónimas, pero 
LA REGULACIÓN COMUNITARIA Y ESPAÑOLA DEL CROWDFUNDING: UNA PERSPECTIVA DESDE LA PROTECCIÓN DE DATOS PERSONALES - FrANCISCA RAMÓN FeRNÁNDEZ (PP. 45-68)

no lo son. Lo único que tienen en común en que se recurre a ellas en búsqueda de recursos económicos con la finalidad de financiar un proyecto, pero tienen más diferencias que similitudes (Ramón, 2015, p. 247).

El mecenazgo se identifica con la figura del mecenas, del filántropo, y se relación con las bellas artes principalmente. Se conoce como la persona que protege a un artista, en una acepción más amplia.

El mecenazgo dispone de una normativa específica (Álvarez, Merino y Martín, 2020) en el ámbito foral y autonómico (ley $9 / 2014$, de 29 de diciembre, de impulso de la actividad y del mecenazgo cultural en la Comunitat Valenciana; ley 3/2015, de 23 de marzo, por la que se regula el consumo cultural y el mecenazgo cultural, científico y de desarrollo tecnológico y se establecen medidas tributarias de la Comunidad Autónoma de las Illes Balears; ley 6/2015, de 30 de marzo, por la que se regula el mecenazgo deportivo y se establecen medidas tributarias de la Comunidad Autónoma de las Illes Balears; ley foral 8/2014, de 16 de mayo, reguladora del mecenazgo cultural y de sus incentivos fiscales en la Comunidad Foral de Navarra; ley 20/2018, de 25 de julio, del mecenazgo cultural, científico y deportivo no profesional en la Comunitat Valenciana y ley 9/2019, de 13 de diciembre, de mecenazgo cultural de Castilla-La Mancha).

Precisamente, la ley 9/2014 define el mecenazgo cultural en su artículo 2 como "toda contribución privada que tenga como finalidad promover o desarrollar cualquier actividad, patrimonio o infraestructura cultural, científica y deportiva", y al mecenas como la persona física o jurídica que realiza dicha contribución, principalmente en dinero, en favor de esa actividad, patrimonio o infraestructura.

De igual modo, disponen de una regulación propia en materia fiscal como es la ley 49/2002, de 23 de diciembre, de régimen fiscal de las entidades sin fines lucrativos y de los incentivos fiscales al mecenazgo; real decreto 1270/2003, de 10 de octubre, por el que se aprueba el reglamento para la aplicación del régimen fiscal de las entidades sin fines lucrativos y de los incentivos fiscales al mecenazgo; real decreto 1804/2008, de 3 de noviembre, por el que se desarrolla la ley 36/2006, de 29 de noviembre, de medidas para la prevención del fraude fiscal, se modifica el reglamento para la aplicación del régimen fiscal de las entidades sin fines lucrativos y de los incentivos fiscales al mecenazgo, aprobado por el real decreto $1270 / 2003$, y se modifican y aprueban otras normas tributarias.

También se diferencia del denominado contrato de patrocinio, en los que se tendrá en cuenta lo indicado en la ley $7 / 2010$, de 31 de marzo, general de la comunicación audiovisual y la ley 34/1988, de 11 de noviembre, general de publicidad. 
Precisamente la ley $7 / 2010$ considera al patrocinio cultural cualquier contribución de una institución, empresa o fundación a la producción de obras audiovisuales, programas de radio y televisión y/o contenidos digitales de temática cultural, social o de promoción del deporte, con la finalidad de promocionar su actividad, marca y/o imagen o como expresión de su responsabilidad social corporativa (Ramón, 2015, p. 250).

Por su parte, la ley 34/1988 regula el contrato de patrocinio, en su artículo 24, y lo señala como aquel contrato por el que el patrocinado a cambio de una ayuda económica para la realización de su actividad deportiva, benéfica, cultural, científica o de otra índole, adquiere el compromiso de colaborar en la publicidad del patrocinador (Ramón, 2015, p. 251).

Si bien es cierto es que, en la actualidad, la utilización como canal de financiación del crowdfunding está en auge, en muchas ocasiones se recurre al mismo cuando "fallan" otras vías de financiación, o bien se trata de obtener fondos no muy elevados para un proyecto concreto. Actualmente, se trata de una práctica consolidada en la financiación de las empresas innovadoras, o start ups y las pequeñas y medianas empresas -PYMES- (Tapia, 2020, p. 1), y que se ha indicado que fomenta la sostenibilidad (Rubio, 2020, p. 61).

Se trata, por tanto, el crowdfunding, de la obtención de fondos mediante aportaciones individuales de los particulares a través de plataformas en línea. Se realiza el contacto entre estos inversores particulares con la persona, el promotor, que necesita los fondos para un determinado proyecto (Goñi, 2020, p. 326).

\section{El reglamento (UE) $2020 / 1503$ relativo a los proveedores europeos de servicios de financiación participativa para empresas}

Recientemente se ha aprobado el reglamento (UE) 2020/1503 del Parlamento Europeo y del Consejo, de 7 de octubre de 2020, referente a los proveedores europeos de servicios de financiación participativa para empresas, y que entrará en vigor el próximo 10 de noviembre de 2021 (Estevan, 2021, p. 25; López, 2021, p. 155). Dicha norma modifica el reglamento (UE) 2017/1129 del Parlamento Europeo y del Consejo, de 14 de junio de 2017, sobre el folleto que debe publicarse en caso de oferta pública o admisión a cotización de valores en un mercado regulado y por el que se deroga la directiva 2003/71/CE, y la directiva (UE) 2019/1937 del Parlamento Europeo y del Consejo, de 23 de octubre de 2019, relativa a la protección de las personas que informen sobre infracciones del derecho de la unión - PE/78/2019/ $\mathrm{REV} / 1-$.

El texto de la norma comunitaria se estratifica en diversos aspectos (Tapia, 2020, p. 2): proveedores de los servicios de financiación participativa; reserva de la 
actividad en favor de los intermediarios autorizados; necesidad de que acrediten unas condiciones de acceso los intermediarios a la actividad de prestación de los servicios de financiación participativa con la finalidad de conseguir la autorización de la administración y las condiciones para ejercer su actividad.

Otra norma de aplicación es la directiva (UE) 2020/1504 del Parlamento Europeo y del Consejo, de 7 de octubre de 2020, por la que se modifica la directiva 2014/65/UE relativa a los mercados de instrumentos financieros - $\mathrm{PE} / 36 / 2020$ / INIT—. Esta última directiva modificó en su momento la directiva 2002/92/CE y la directiva 2011/61/UE.

Como veremos a continuación, en España existe una regulación del crowdfunding, pero esta normativa comunitaria pretende una unificación y armonización de la normativa (Tapia, 2020, p. 1), ya que está regulado también en otros países (Palomino, 2018, p. 959), por ejemplo, Italia (Guerrieri, 2018, p. 77) o Estados Unidos (Pastor, 2020, p. 1225).

Como señala el considerando 1 del reglamento (UE) 2020/1503:

La financiación participativa es, cada vez en mayor medida, una forma consolidada de financiación alternativa para las empresas emergentes y las pequeñas y medianas empresas (pymes), en las que lo habitual es recibir inversiones de pequeño calado. La financiación participativa representa un tipo cada vez más importante de intermediación en la que un proveedor de servicios de financiación participativa opera, sin asumir ningún riesgo propio, a través de una plataforma digital abierta al público, con objeto de poner en contacto o facilitar el contacto a inversores o prestamistas potenciales con empresas que busquen financiación. Dicha financiación podría adoptar la forma de préstamos o de adquisición de valores negociables o de otros instrumentos admitidos para la financiación participativa. Por tanto, procede incluir en el ámbito de aplicación del presente reglamento tanto la financiación participativa de crédito como la financiación participativa de inversión, ya que se pueden estructurar esos tipos de financiación participativa como alternativas de financiación comparables.

La regulación comunitaria tiene un triple objetivo (Molina, 2020, p. 1):

A) Acceso a nuevas formas de financiación transfronteriza.

B) Incremento de la seguridad jurídica.

C) Mejorar la protección de los inversores. 
No obstante, el reglamento (UE) 2020/1503 no se aplica en los supuestos de servicios de financiación participativa que se presten a promotores de proyectos que sean consumidores según indica la directiva 2008/48/CE del Parlamento Europeo y del Consejo, de 23 de abril de 2008, relativa a los contratos de crédito al consumo y por la que se deroga la directiva 87/102/CEE del Consejo, en su artículo 3, letra a); tampoco se aplica a otros servicios relacionados con los indicados en el artículo 2, apartado 1, letra a), y que se presten de acuerdo con lo indicado en el derecho nacional, ni tampoco se aplica a las ofertas de financiación participativa cuyo importe sea superior a 5.000.000 euros calculado a lo largo de un periodo de 12 meses.

Nos interesa destacar los principales aspectos del reglamento (UE) 2020/1503:

1) Se establece una definición respecto de lo que se entiende como servicio de financiación participativa, el concepto de préstamo, la gestión individualizada de carteras de préstamos, las plataformas de financiación participativa y el proveedor de servicios de financiación participativa.

Interesa mencionar que las plataformas se consideran como sistemas de información basadas en internet, a las que se pueda acceder de forma pública y que están explotadas o gestionadas por un proveedor de servicios de financiación participativa que es una persona jurídica que presta servicios de financiación participativa.

Estos servicios de financiación participativa son aquellos que ponen en conexión intereses de inversores y promotores de proyectos de financiación de empresas utilizando las plataformas. Se integran por dos tipos de actividades que señala el mencionado reglamento (UE) 2020/1503: por un lado, concesión de préstamos; por otro lado, colocación de valores negociables "y de instrumentos admitidos para la financiación participativa emitidos por los promotores de proyectos o por una entidad instrumental, y la recepción y transmisión de órdenes de clientes".

2) En cuanto a las partes que intervienen, se establece una limitación en el caso de no acreditado de mil euros o bien el $5 \%$ de los activos por proyecto, siendo una cantidad inferior a la establecida por la ley española (Molina, 2020, p. 1).

3) Establecimiento por parte de los proveedores de servicios de financiación participativa de procedimientos que sean eficaces y transparentes para la tramitación de forma rápida e imparcial y coherente de las reclamaciones de los clientes. 
4) Previsión de un sistema de gestión eficaz y prudente para evaluar los riesgos relacionados con los préstamos propuestos a través de las plataformas de financiación participativa. Se contempla una prueba inicial de conocimientos y simulación de la capacidad de soportar las pérdidas, por parte de los inversores no experimentados potenciales antes de acceder a la invertir en proyectos de financiación participativa. Los proveedores de servicios evaluarán si los servicios que ofrecen son adecuados para los inversores no experimentados potenciales. Solicitarán información sobre experiencia, objetivos, situación financiera y la comprensión de los riesgos que asumen con la inversión. Estos proveedores revisarán cada dos años con el inversor tras la evaluación inicial que hayan realizado. También revisarán, pero cada año, la simulación a la que se refiere el artículo 21 del reglamento (UE) 2020/1503.

5) Se indican las condiciones específicas en el caso de la gestión individualizada de carteras de préstamo en el que el inversor otorgará un mandato que especificará los parámetros de prestación del servicio. Deberá incluir por lo menos dos criterios de los siguientes, según dispone el artículo 6 del reglamento (UE) 2020/1503:

a) el tipo de interés mínimo y máximo que se pagará en el marco de cada préstamo facilitado al inversor;

b) la fecha de vencimiento mínima y máxima de los préstamos facilitados al inversor;

c) la gama y la distribución de cualquier categoría de riesgo aplicable a los préstamos, y

d) en caso de que se ofrezca un tipo objetivo anual de rentabilidad de la inversión, la probabilidad de que los préstamos seleccionados permitan al inversor alcanzar el tipo objetivo con un grado de certeza razonable.

Se considera como inversor experimentado, tal y como recoge el anexo del reglamento (UE) 2020/1503, el que es consciente de los riesgos que asume con la inversión y dispone de recursos suficientes para asumirlos sin necesidad de exponerse a consecuencias financieras excesivas.

Serán calificados como tales los que cumplan los criterios que indica el texto legal y que mencionamos a continuación:

1) Personas jurídicas que cumplan al menos uno de los siguientes criterios:

a) recursos propios de al menos 100.000 euros; 
b) volumen de negocios netos de al menos 2.000 .000 euros;

c) balance de al menos 1.000 .000 euros.

2) Personas físicas que cumplan al menos dos de los siguientes criterios:

a) ingresos brutos personales de al menos 60.000 euros por ejercicio fiscal, o una cartera de instrumentos financieros, definida como la inclusión de depósitos de efectivo y activos financieros, superior a 100.000 euros;

b) el inversor trabaja o ha trabajado en el sector financiero al menos durante un año en un puesto profesional que requiera tener conocimiento de las operaciones o servicios previstos, o ha ocupado un puesto ejecutivo durante al menos 12 meses en una persona jurídica de las determinadas en el punto 1 ;

c) el inversor ha realizado operaciones de volumen significativo en los mercados de capitales con una frecuencia media de 10 por trimestre durante los cuatro trimestres anteriores.

Respecto a la protección del inversor y siguiendo a Tapia (2020, p. 4), podemos indicar las siguientes medidas contempladas en el reglamento (UE) 2020/1503: transparencia de los proveedores para con los inversores mediante información y publicidad, y recíprocamente de los inversores para con los proveedores mediante la prueba de conocimientos y la simulación de la capacidad de soporte de pérdidas.

Otro de los elementos de protección es la ficha de datos fundamentales de la inversión (a la que también haremos referencia en materia de protección de datos) que se debe facilitar a los inversores potenciales por parte del proveedor de servicios de financiación participativa. Resulta de interés como señala Tapia (2020, p. 4) la cláusula de exención de responsabilidad y la advertencia del riesgo.

En la actualidad, y además con la situación de crisis sanitaria por la pandemia de COVID 19, se presume que se utilizará esta vía de financiación en los actuales mercados (Tapia, 2020, p. 2) ya que se trata de un instrumento de financiación basado en la digitalización colectiva. Consideramos que no solo se puede utilizar en la actual crisis financiera en la que estamos inmersos, sino que también puede ser una herramienta válida para salir de la misma precisamente por parte de las pequeñas y medianas empresas (PYMES) (Tapia, 2020, p. 2).

No obstante, este instrumento de financiación a través de la participación colectiva debe ser asumido en términos "realistas", para evitar desarrollar falsas expectativas en los mercados - algún autor, como Tapia (2020, p. 2), refiere al riesgo 
LA REGULACIÓN COMUNITARIA Y ESPAÑOLA DEL CROWDFUNDING: UNA PERSPECTIVA

DESDE LA PROTECCIÓN DE DATOS PERSONALES - FRANCISCA RAMÓN FERNÁNDEZ (PP. 45-68)

de proyectos que se conviertan en "cuentos de la lechera" - e, incluso, derivar en comportamientos fraudulentos.

\section{La ley 5/2015 del 27 de abril, de fomento de la financiación empresarial}

Esta norma, siguiendo lo que ya indicó el Proyecto de ley de fomento de financiación empresarial (Álvarez, 2014; Carrasco, 2014) regula en el artículo 46 el régimen jurídico que se aplica a las denominadas plataformas de financiación participativa en el derecho español. Se trata de dar cabida a las actividades que hemos visto constituye el denominado como crowdfunding (Gimeno, 2014; Lázaro, 2018, p. 19; Macanás, 2018, p. 73; Navarro, 2018, p. 217; González, 2019, p. 413), y que es objeto de regulación en sus modalidades de inversión o equity crowdfunding o préstamo o crowdlending (Molina, 2020, p. 1).

El surgimiento de esta fórmula para financiar proyectos radica en la utilización de las nuevas tecnologías de la información y comunicación (TIC) (AA.VV., 2019) y forma parte de lo que se conoce como participación pública para obtener fondos con la finalidad de desarrollar una actividad. Se trata de una forma de economía colaborativa (AA.VV., 2018), y es la fórmula más utilizada por parte de los denominados emprendedores (Alemany y Bultó, 2014, p. 7), y como alternativa para conseguir financiación cuando otras vías no resultan viables, así como también una alternativa al mecenazgo privado de las grandes empresas (Gutiérrez, 2014, p. 10; Alonso, 2020: 184). Se trata de potenciar la microinversión (Ramos, 2013, p. 54).

Esta forma de obtener financiación es preciso, como hemos indicado, diferenciarla de otras fórmulas, en las que prevalece un interés de benefactor. En el caso de las plataformas por internet con la participación pública hay un proyecto que resulta de interés para el que lo financia, además de ser una manera más adaptada a las tecnologías, en las que a través de redes sociales se hace difusión de las propuestas.

No obstante, la ley $5 / 2015$ presenta un sesgo en su aplicación, ya que se limita a la actividad en la que prime un componente financiero, es decir, hay un inversor que desea obtener una remuneración dineraria a cambio de su participación. Por tanto, se excluye la actividad del crowdfunding mediante compraventa o donación (Alonso, 2018, p. 339; Borrallo, 2020, p. 299; Campuzano, 2020, p. 238; Cuena, 2020, p. 361; De la Vega, 2018, p. 47).

Uno de los ámbitos donde se ha utilizado esta forma de financiación ha sido el cultural, en especial en materia audiovisual tras la situación de crisis económica (Guzmán, 2014, p. 17), como una nueva forma de producir, distribuir y exhibir películas (Altabás, 2014, p. 390). 
El artículo 46 de la ley 5/2015 se refiere a las plataformas de financiación participativa y aporta una definición que nos resulta de interés indicar:

(...) las empresas autorizadas cuya actividad consiste en poner en contacto, de manera profesional y a través de páginas web u otros medios electrónicos, a una pluralidad de personas físicas o jurídicas que ofrecen financiación a cambio de un rendimiento dinerario, denominados inversores, con personas físicas o jurídicas que solicitan financiación en nombre propio para destinarlo a un proyecto de financiación participativa, denominados promotores.

Lo primero que nos llama la atención es que se trata de empresas que deben estar autorizadas (Sánchez, 2020, p. 1141; Tapia, 2020b, p. 1), y que su actividad consiste en poner en contacto a inversores y promotores, pero siempre con una finalidad lucrativa. Es decir, el inversor busca un rendimiento y el promotor tiene un proyecto que quiere financiar. Las plataformas operan como intermediarios financieros (Molina, 2020, p. 1), ya que ponen en contacto al promotor e inversor y quedan bajo la autorización y supervisión de la Comisión Nacional del Mercado de Valores y del Banco de España. Como advierte Molina (2020, p. 1), "esta supervisión se centra, de nuevo, en las plataformas, en ningún caso en los proyectos individuales".

El preámbulo de la ley $5 / 2015$ nos proporciona las dos notas distintivas de estas plataformas:

a) participación masiva de inversores;

b) una inversión que no está exenta de riesgo.

Las plataformas de financiación participativa disponen en la ley 5/2015 de un específico régimen jurídico, así como la reserva a las entidades que sean autorizadas de conformidad con lo que dispone la ley 20/2013, de 9 de diciembre, de garantía de la unidad de mercado, en su artículo 5 respecto a los principios de necesidad y proporcionalidad:

Las autoridades competentes que en el ejercicio de sus respectivas competencias establezcan límites al acceso a una actividad económica o su ejercicio de conformidad con lo previsto en el artículo 17 de esta ley o exijan el cumplimiento de requisitos para el desarrollo de una actividad, motivarán su necesidad en la salvaguarda de alguna razón imperiosa de interés general de entre las comprendidas en el artículo 3.11 de la ley 17/2009, de 23 de noviembre, sobre el libre acceso a las actividades de servicios y su ejercicio. 
Cualquier límite o requisito establecido conforme al apartado anterior, deberá ser proporcionado a la razón imperiosa de interés general invocada, y habrá de ser tal que no exista otro medio menos restrictivo o distorsionador para la actividad económica.

El objetivo de esta regulación, como expresa el preámbulo de la ley 5/2015, consiste "en aclarar la regulación que ya hoy debiera resultar aplicable" y "en ajustar la misma en aras del difícil equilibrio entre una regulación que potencie esta actividad y a la vez garantice un adecuado nivel de protección del inversor".

Como expone Molina (2020, p. 1) en la ley 5/2015 se indican las condiciones que tanto promotores como los proyectos deben cumplir, "a través de obligaciones de control directo por parte de las plataformas", así como los "límites de inversión de los inversores no acreditados" frente a los que sí lo están.

Se regulan en el capítulo I, por su parte, el ámbito de aplicación territorial (artículo 47), la reserva de actividad y denominación (artículo 48), los proyectos de financiación participativa (artículo 49), las formas de financiación participativa (artículo 50), los servicios de las plataformas de financiación participativa (artículo 51) y las prohibiciones (artículo 52).

El capítulo II se dedica a la autorización y registro, comprendiendo los artículos 53 a 59, en el que se contiene la regulación de la misma, además de los requisitos para ejercer la actividad, los requisitos financieros, la solicitud de autorización e inscripción, la modificación de la autorización, y la revocación, suspensión y renuncia de la autorización.

El capítulo III se ocupa de las normas de conducta, en los artículos 60 a 65 indicando los principios generales, las obligaciones de información general, los conflictos de interés, los proyectos vinculados, la publicidad y la conservación de información.

El capítulo IV trata sobre los promotores y los proyectos y contiene los artículos 66 a 80, en el que se recogen los requisitos generales (diligencia en la admisión y comprobación de la identidad del promotor, requisitos de los promotores, límites al número de proyectos e importe máximo de captación, límites temporales y cuantitativos del proyecto, información del proyecto, responsabilidad de la plataforma de financiación participativa respecto de la información del proyecto, obligaciones adicionales respecto de la información y responsabilidad de los promotores por la información publicada), los requisitos aplicables a los préstamos (idoneidad de los préstamos concedidos, información sobre el promotor que capta financiación mediante préstamos e información sobre los préstamos) y los requisitos aplicables a las acciones, participaciones u otros valores representativos 
de capital y obligaciones (idoneidad de los valores emitidos, información sobre el promotor que emite valores, información sobre la oferta de valores y requisitos de los estatutos sociales de los promotores).

El capítulo V, que comprende los artículos 81 a 88, se centra en la protección del inversor y se refiere a los tipos de inversores, límites a la inversión en proyectos publicados en plataformas de financiación participativa, los requisitos de información previos a la inversión, expresiones del inversor, aplicación del derecho de protección de los consumidores y usuarios, aplicación del derecho de consumo a las plataformas de financiación participativa, prohibición de préstamos o créditos hipotecarios en proyectos con consumidores, y advertencias a realizar.

El capítulo VI se ocupa de la supervisión, inspección y sanción, en los artículos 89 a 93, indicando el régimen de inspección y sanción, las facultades de la comisión nacional del mercado de valores y cooperación con el banco de España, las comunicaciones a la comisión nacional del mercado de valores, las infracciones y sanciones.

También interesa destacar su régimen fiscal y tributario cuyas peculiaridades ha puesto de manifiesto la doctrina (Álvarez, 2018, p. 79; Ortiz, 2018, p. 189; Pedreira, 2018, p. 135; Soto, 2018, p. 50), así como el ámbito penal (Rubio, 2018, p. 161).

\section{La protección de datos personales en el crowdfunding}

La peculiaridad de esta modalidad de financiación es que se realiza a través de plataformas, es decir, a través de internet. Siguiendo lo indicado en el texto constitucional español, en su artículo 18.4, "la ley limitará el uso de la informática para garantizar el honor y la intimidad personal y familiar de los ciudadanos y el pleno ejercicio de sus derechos"; es por ello que hay que tener en cuenta lo indicado en el reglamento (UE) 2016/679 del Parlamento Europeo y del Consejo de 27 de abril de 2016 relativo a la protección de las personas físicas en lo que respecta al tratamiento de datos personales y a la libre circulación de estos datos y por el que se deroga la directiva 95/46/CE y en la ley orgánica 3/2018, de 5 de diciembre, de protección de datos personales y garantía de los derechos digitales, tanto desde el punto de vista del inversor como del promotor (Martínez, 2020, p. 625).

En el caso de las plataformas de financiación participativa y su presencia en las redes, los datos personales que se faciliten en los formularios al efecto deben ser protegidos, ya que precisamente la mencionada ley orgánica 3/2018 tiene como objeto "adaptar el ordenamiento jurídico al reglamento (UE) 2016/679", y que el "derecho fundamental de las personas físicas a la protección de datos personales, amparado por el artículo 18.4 de la constitución, se ejercerá con arreglo a lo 
establecido en el reglamento (UE) 2016/679". Además, las plataformas de financiación participativa deben cumplir unas normas de conducta (Sánchez, 2018, p. 303).

Se trata de plataformas que prestan servicios digitales de forma online (Alonso, 2020) y por ello con la prestación del consentimiento expreso en el formulario se están facilitando los datos personales para que se utilicen y formen parte de un fichero (Reduce, s/f.). También se menciona por parte de la doctrina la necesidad de evaluación del riesgo del crédito y la privacidad dentro de la ley orgánica 3/2018 (Alonso, 2020, p. 441), así como incrementar la transparencia (Hernández, 2020, p. 161).

Interesa destacar lo indicado en el artículo 54 de la ley 5/2015 que establece la inscripción en el registro de la comisión nacional del mercado de valores de las plataformas, debiendo constar los datos actuales de la denominación social, la dirección de dominio de internet y domicilio social de la plataforma, así como la identidad de los administradores y una relación de los socios con participación significativa.

También se mencionan los datos en el caso del artículo 57 de la ley $5 / 2015$ respecto a la solicitud de autorización e inscripción de una plataforma de financiación participativa en la que se indica datos referentes a socios y administradores, entre otros.

También en relación a los datos proporcionados en las plataformas sería de aplicación lo indicado en la normativa de protección de datos personales en relación con el acceso, rectificación, cancelación y oposición.

El artículo 90 de la ley 5/2015 respecto a las facultades de la comisión nacional del mercado de valores y cooperación con el banco de España indica que aquella podrá solicitar datos y documentos que se hallen en disposición del banco de España.

El artículo 98.5 de la ley 24/1988, de 28 de julio, del mercado de valores (actualmente derogada por el real decreto legislativo 4/2015, de 23 de octubre, por el que se aprueba el texto refundido de la ley del mercado de valores) indicaba que la comisión nacional del mercado de valores podía publicar la incoación de los expedientes sancionadores, después de notificado a los interesados, una vez resuelto los aspectos confidenciales de su contenido y siempre que se disociara los datos personales protegidos, salvo en lo que se refiere al nombre de los infractores. Tal y como señalaba el precepto, "la publicación se decidirá previa ponderación, suficientemente razonada, entre el interés público, atendiendo a los efectos favorables que, en conjunto, genere sobre la mejor transparencia y funcionamiento de 
los mercados de valores y la protección de los inversores, y el perjuicio que cause a los infractores".

Se entiende que tras la ley orgánica 3/2018 los datos personales están protegidos y no pueden ser publicados, sino que deberán ser anonimizados a efectos de cumplir con la normativa indicada. Esta necesidad de anonimizar la información personal también se realiza en el caso de las sentencias judiciales, por lo que sería aplicable de forma analógica. Es preciso que con dicha anonimización no se pueda identificar a la persona, y además se debe tener en cuenta el artículo 93 de la ley orgánica 3/2018 respecto al derecho al olvido en búsquedas de internet, y el artículo 94 del mismo texto legal relativo al derecho al olvido en servicios de redes sociales y servicios equivalentes.

En la regulación comunitaria a la que hemos hecho referencia en este trabajo se hace mención de la ficha de datos fundamentales de la inversión. Este documento deberá ser elaborado por el promotor del proyecto para cada oferta de financiación y "facilitar a todo inversor potencial el proveedor de servicios de financiación participativa" (Tapia, 2020a, p. 5).

Y respecto a la publicación de las decisiones en las que se imponga una sanción administrativa respecto a una infracción, siguiendo lo indicado anteriormente respecto a la ley orgánica $3 / 2018$, el reglamento (UE) 2020/1503, en su artículo 42.2, indica que en los casos en que se considere que la publicación de la identidad de las entidades jurídicas o los datos personales de las personas físicas sea desproporcionada, o cuando la publicación ponga en peligro una investigación en curso, podrán las autoridades realizar la publicación de la decisión referente a la imposición "de una sanción o medida de forma anonimizada, de un modo que sea conforme con la legislación nacional, siempre que dicha publicación anonimizada garantice la protección eficaz de los correspondientes datos personales".

Además, se precisa en el artículo 42.4 del reglamento (UE) 2020/1503 que las autoridades competentes garantizarán que la información a la que se refiere el precepto se mantendrá en la web durante un plazo de cinco años mínimo.

Sin embargo, los datos personales que se incluyan en la publicación "solamente se mantendrán en el sitio web oficial de la autoridad competente durante el periodo necesario de conformidad con las normas en materia de protección de datos que sean aplicables".

\section{Conclusiones}

La necesidad de encontrar nuevas vías de financiación en la era internet ha hecho que el crowdfunding sea utilizado con dicha finalidad. En España se reguló 
a través de la ley 5/2015 mediante las denominadas plataformas de financiación participativa.

Se trata de una figura que es preciso diferenciarla de otras formas de financiación, como es el contrato de patrocinio o el mecenazgo, del que participa en algunas notas.

La reciente regulación de la Unión Europea con el reglamento (UE) 2020/1503 y la directiva (UE) 2020/1504 supone una regulación que va a ser aplicable a España, con la consiguiente necesidad de incorporación de la directiva, y la aplicación directa del reglamento. Hemos visto que hay diferencias notables, principalmente en lo referente a requisitos de carácter económico, con la legislación nacional española, por lo que sería preciso la adaptación correspondiente.

El crowdfunding representa una vía alternativa de financiación que en los últimos años ha sido objeto de una regulación específica, muestra de su auge en el ámbito de su aplicación a diversos supuestos.

El crowdfunding no solo goza de ventajas, sino también de inconvenientes, como hemos tenido oportunidad de indicar. La capacidad de asunción del riesgo es diferente según los recursos económicos del inversor y del promotor.

\section{Bibliografía}

AA.VV. (2018). Aspectos legales de la economía colaborativa y bajo demanda en las plataformas digitales. S. Rodríguez Marín, A. Muñoz García y F. Rodríguez Martínez (coord.). Madrid: Wolters Kluwer.

AA.VV. (2019). $4^{a}$. Revolución industrial: la fiscalidad de la sociedad digital y tecnológica en España y Latinoamérica. C. García Novoa (dir.), Cizur Menor: Aranzadi Thomson Reuters.

Alemany, L. y Bultó, I. (2014). “Crowdfunding”: una nueva forma de financiación para los emprendedores. Harvard Deusto business review (237) (pp. 6-19). España: Planeta.

Alonso Arroba, P. (2020). TIC, redes sociales y crowdfunding, una alternativa al mecenazgo privado de las grandes empresas. PH: Boletín del Instituto Andaluz del Patrimonio Histórico (99) (pp. 184-185). Recuperado de https://www.iaph.es/revistaph/index.php/revistaph/article/view/4576 [Fecha de consulta: 02/01/2021].

Alonso Martínez, C. (2020). Evaluación del riesgo de crédito: Big Data y privacidad en el marco de la ley $3 / 2018$, de 5 de diciembre de protección de datos 
personales y garantía de los derechos digitales. En M. Cuena Casas (dir.), Aspectos legales de la financiación en masa o crowdfunding (pp. 441-464). Valencia: Tirant lo Blanch.

Alonso Pérez, M. T. (2020). Servicios digitales prestados por plataformas online de crowdfunding-donación. En M. T. Alonso Pérez; E. Hernández Sáinz y M. J. Santos Morón (dir.), Servicios digitales, condiciones generales y transparencia (pp. 21-52). Cizur Menor: Aranzadi Thomson Reuters.

Altabás Fernández, C. (2014). Autofinanciación y crowdfunding: Nuevas vías de producción, distribución y exhibición del cine español independiente tras la crisis financiera española. Historia y comunicación social (19) (pp. 387-399). Madrid: Universidad Complutense de Madrid.

Álvarez, B.; Merino, E. y Martín, P. (2020). Las posibilidades de la actual regulación del mecenazgo en España. PH: Boletín del Instituto Andaluz del Patrimonio Histórico, (99) (pp. 164-166). Recuperado de https://www.iaph.es/revistaph/index.php/revistaph/article/view/4563 [Fecha de consulta: 01/01/2021].

Álvarez Pérez, M. B. (2018). Una visión del crowfunding desde la contabilidad. En J. Pedreira Menéndez (dir.), Fiscalidad de la colaboración social (pp. 77-99). Cizur Menor: Editorial Aranzadi Thomson-Reuters.

Álvarez Royo-Villanova, S. (2014). La propuesta de regulación de la inversión en masa o equity crowdfunding. Diario La Ley (8320). España: Wolters Kluwer.

Aniorte Cánovas, I. (2013). El crowdfunding, una ayuda económica y colectiva para los museos. RDM. Revista de Museología: Publicación científica al servicio de la comunidad museológica (57) (pp. 9-13). España: Asociación española de Museólogos.

Alonso Espinosa, F. J. (2018). Protección de la inversión a través de plataformas de financiación participativa. En E. J. Lázaro Sánchez y F. L de la Vega García (dir.), Crowfunding: cooperación colectiva al servicio de la financiación (pp. 339-360). Cizur Menor: Editorial Aranzadi.

Borrallo Fernández, C. (2020). Régimen general del crowdfunding: el promotor y el inversor. En M. Cuena Casas (dir.), Aspectos legales de la financiación en masa o crowdfunding (pp. 299-321). Valencia: Tirant lo Blanch.

Campuzano Laguillo, A. B. (2020). Las plataformas de financiación participativa. En M. Cuena Casas (dir.), Aspectos legales de la financiación en masa o crowdfunding (pp. 238-298). Valencia: Tirant lo Blanch. 
Carrasco Perera, A. (2014). El "crowdfunding" que viene. Actualidad jurídica Aranzadi (883) (p. 3). Cizur Menor: Aranzadi Thomson Reuters.

Cuena Casas, M. (2020). Régimen jurídico aplicable a los contratos de préstamo a través de plataformas de financiación participativa. En M. Cuena Casas (dir.), Aspectos legales de la financiación en masa o crowdfunding (pp. 361-397). Valencia: Tirant lo Blanch.

De la Vega García, F. L. (2018). Los mercados del crowdfunding y su protección jurídica. En E. J. Lázaro Sánchez y F. L de la Vega García (dir.), Crowfunding: cooperación colectiva al servicio de la financiación (pp. 47-71). Cizur Menor: Editorial Aranzadi.

Equipo Hispania Nostra (2018). La r-evolución del mecenazgo para la salvaguarda del patrimonio cultural. PH: Boletín del Instituto Andaluz del Patrimonio Histórico (95) (49-50). Recuperado de La r-evolución del mecenazgo para la salvaguarda del patrimonio cultural | revista PH (iaph.es) [Fecha de consulta: 01/01/2021].

Estevan de Quesada, C. (2021). Crowdfunding financiero en la Unión Europea: el Reglamento (UE) 2020/1503 relativo a los proveedores europeos de servicios de financiación participativa para empresas. Revista española de capital riesgo (1) (pp. 25-41).

Gimeno Ribes, M. (2014). Aproximación a la naturaleza jurídica del "crowdfunding". Revista de Derecho Mercantil (291) (pp. 451-490). Cizur Menor: Aranzadi Thomson Reuters.

González Álvarez-Silvosa, V. A. (2019). Concepto y régimen jurídico del crowdfunding. En. I. González Pulido (coord.) y F. Bueno de Mata (dir.), FODERTICS 7.0: estudios sobre derecho digital (pp. 413-422). Granada: Comares.

González Sánchez, M. y Palomo Torres, M. B. (2014). Conocimiento y valoración del crowdfunding en Comunicación: La visión de profesionales y futuros periodistas. Comunicar: Revista científica iberoamericana de comunicación y educación (43) (pp. 101-110). España: Grupo Comunicar.

Goñi Rodríguez de Almeida, M. (2020). El crowdfunding como herramienta de financiación inmobiliaria: realidades y problemas. Revista de Derecho Civil (5) (pp. 315-364). Recuperado de https://www.nreg.es/ojs/index.php/RDC/article/ view/539/487 [Fecha de consulta: 01/09/2021].

Guerrieri, G. (2018). La disciplina del crowfunding en Italia. En J. Pedreira Menéndez (dir.), Fiscalidad de la colaboración social (pp. 77-99). Cizur Menor: Editorial Aranzadi Thomson-Reuters. 
Gutiérrez Rodríguez, J. (2014). El "crowdfunding”, mucho más que un mecenazgo. Cont4bl3 (49) (pp. 10-11). Barcelona: Asociación profesional de expertos contables y tributarios de España.

Guzmán Raja, I. (2014). El "crowdfunding": una alternativa de financiación en tiempos de crisis. AECA: Revista de la Asociación Española de Contabilidad y Administración de Empresas (106) (pp. 17-20). España: Asociación española de contabilidad y administración de empresas.

Hernández Sáinz, E. (2020). Mecanismos para garantizar un adecuado nivel de transparencia en las solicitudes de financiación empresarial a través de plataformas de financiación participativa (crowdfunding). En M. T. Alonso Pérez, E. Hernández Sáinz y M. J. Santos Morón (dir.), Servicios digitales, condiciones generales y transparencia (pp. 161-194). Cizur Menor: Aranzadi Thomson Reuters.

Lázaro Sánchez, E. J. (2018). Crowdfunding: una fórmula de cooperación económica en la era digital. En E. J. Lázaro Sánchez y F. L de la Vega García (dir.), Crowfunding: cooperación colectiva al servicio de la financiación (pp. 19-46). Cizur Menor: Editorial Aranzadi.

López Ortega, R. (2021). Las plataformas de financiación participativa a la luz de la nueva regulación europea del crowdfunding (El Reglamento UE 2020/1503, de 7 de octubre de 2020, sobre los proveedores europeos de servicios de financiación participativa para empresas). Revista de derecho bancario y bursátil (162) (pp. 155-204).

Macanás Vicente, G. (2018). Calificación y caracteres del contrato de mediación con la plataforma de crowdfunding. En E. J. Lázaro Sánchez y F. L de la Vega García (dir.), Crowfunding: cooperación colectiva al servicio de la financiación (pp. 73-103). Cizur Menor: Editorial Aranzadi.

Martínez, R. (2020). Crowdfunding y protección de datos. En M. Cuena Casas (dir.), Aspectos legales de la financiación en masa o crowdfunding (pp. 625-648). Valencia: Tirant lo Blanch.

Molina Martín, M. (2020). Claves para entender el reglamento europeo del crowdfunding. Legal Today (pp. 1-3). Recuperado de https://www.legaltoday.com/ practica-juridica/derecho-mercantil/mercantil/claves-para-entender-el-reglamento-europeo-de-crowdfunding-2020-12-02/ [Fecha de consulta: 04/01/2021].

Navarro Matamoros, L. (2018). Concepto y clases. En E. J. Lázaro Sánchez y F. L de la Vega García (dir.), Crowfunding: cooperación colectiva al servicio de la financiación (pp. 217-243). Cizur Menor: Editorial Aranzadi. 
Ortiz Martínez, E. (2018). Contabilidad y crowdfunding. En E. J. Lázaro Sánchez y F. L de la Vega García (dir.), Crowfunding: cooperación colectiva al servicio de la financiación (pp. 189-214). Cizur Menor: Editorial Aranzadi.

Palomino Guerrero, M. (2018). Comentarios a la ley para regular las instituciones de tecnología financiera. Revista de la Facultad de Derecho de México, 68 (271) (pp. 959-964). Recuperado de http://www.revistas.unam.mx/index.php/rfdm/article/view/65369 [Fecha de consulta: 01/01/2021].

Pastor Núñez de Castro, E. (2020). Análisis de los límites de inversión y mecanismos de protección del inversor en el crowdfunding: una perspectiva comparada entre Estados Unidos y España. En P. Márquez Lobillo; M. T. Otero Cobos; Z. Bednarz (coord.); M. B. González Fernández y A. Cohen Benchetrit (dir.), Derecho de sociedades: los derechos del socio (pp. 1225-1245). Valencia: Tirant lo Blanch.

Pedreira Menéndez, J. (2018). Fiscalidad de las operaciones de crowdfunding. Alonso Espinosa, F. J. (2018). Protección de la inversión a través de plataformas de financiación participativa. En E. J. Lázaro Sánchez y F. L de la Vega García (dir.), Crowfunding: cooperación colectiva al servicio de la financiación (pp. 135-160). Cizur Menor: Editorial Aranzadi.

Ramón Fernández, F. (2015). Algunas cuestiones del mecenazgo y el patrimonio cultural. Revista Aranzadi de derecho patrimonial (37) (pp. 245-269). Cizur Menor: Aranzadi Thomson Reuters.

Ramos, D. (2013). Microinversores para tus proyectos: el crowdfunding se ha convertido en una buena alternativa para conseguir financiación cuando no se puede obtener por los canales tradicionales. Emprendedores: las claves de la economía y el éxito profesional (184) (pp. 54-56).

Reduce (s/f). ¿Cómo me afecta la LOPD en el crowdfunding? Recuperado de https://reduce.es/me-afecta-la-lopd-crowdfunding/ [Fecha de consulta:02/01/2021].

Roig Telo, A.; Sánchez Navarro, J. y Leibovitz, T. (2012). ¡Esta película la hacemos entre todos! Crowdsourcing y crowdfunding como prácticas colaborativas en la producción audiovisual contemporánea. Icono 14, Ejemplar dedicado a: El cine ante las transformaciones tecnológicas y los flujos comunicativos globales, 10 (1) (pp. 25-40).

Rubio Martín, G. (2020). Análisis del crowdfunding en España: una nueva herramienta social para fomentar la sostenibilidad. REVESCO: revista de estudios cooperativos (135) (pp. 61-70). Recuperado de https://revistas.ucm.es/index.php/ REVE/article/view/69182/4564456553812 [Fecha de consulta: 02/01/2021]. 
Ruiz Gutiérrez, J. M. (2010). Crowdfunding y creative commons: nuevos modelos de financiación y propiedad intelectual para la producción y distribución de proyectos audiovisuales. CDC Cuadernos de Comunicación, (4) (30). Recuperado de http://cdc.escogranada.com/cdc/wp-content/uploads/2010/12/0404cc.pdf [Fecha de consulta: 02/01/2021].

Sánchez Ruiz, M. (2018). Las normas de conducta de las plataformas de financiación participativa. En E. J. Lázaro Sánchez y F. L de la Vega García (dir.), Crowfunding: cooperación colectiva al servicio de la financiación (pp. 303-337). Cizur Menor: Editorial Aranzadi.

Sánchez Ruiz, M. (2020). La (débil) posición jurídica del socio inversor no acreditado en el "equity crowdfunding". En P. Márquez Lobillo; M. T. Otero Cobos y Z. Bednarz (coord.), M. B. González Fernández y A. Cohen Benchetrit (dir.), Derecho de sociedades: los derechos del socio (pp. 1141-1160). Valencia: Tirant lo Blanch.

Rubio Lara, P. A. (2018). Crowdfunding y derecho penal. En E. J. Lázaro Sánchez y F. L de la Vega García (dir.), Crowfunding: cooperación colectiva al servicio de la financiación (pp. 161-187). Cizur Menor: Editorial Aranzadi.

Soto Moya, M. del M. (2018). Tributación del crowfunding. Valencia: Tirant lo Blanch.

Tapia Hermida, A. J. (2020a). Decálogo de la nueva regulación europea del crowfunding. Diario La Ley (9736) (pp. 1-5). Recuperado de https://www.iimv. org/iimv-wp-1-0/resources/uploads/2020/11/AJ-Tapia.-Dec\%C3\%Allogo-de-lanueva-regulaci\%C3\%B3n-europea-del-crowfunding.-Diario-La-Ley-n\%C2\%BA9730-Tribuna-06.11.20.pdf [Fecha de consulta: 31/12/2020].

Tapia Hermida, A. J. (2020b). La nueva regulación europea del crowfunding: El reglamento (UE) 2020/1503, de 7 de octubre de 2020, sobre los proveedores europeos de servicios de financiación participativa para empresas. El blog de Alberto J. Tapia Hermida (pp. 1-8). Recuperado de http://ajtapia.com/2020/10/la-nueva-regulacion-europea-del-crowfunding-el-reglamento-ue-2020-1503-de-7-deoctubre-de-2020-sobre-los-proveedores-europeos-de-servicios-de-financiacionparticipativa-para-empresas/ [Fecha de consulta: 03/01/2020].

\section{Legislación}

Constitución Española de 29 de diciembre de 1978 (BOE núm. 311, de 29/12/1978).

Directiva 2008/48/CE del Parlamento Europeo y del Consejo, de 23 de abril de 2008, relativa a los contratos de créditos al consumo y por la que se deroga la 
Directiva 87/102/CEE del Consejo (DOUE L 133, de 22 de mayo de 2008, páginas 66-92).

Directiva 2014/65/UE del Parlamento Europeo y del Consejo, de 15 de mayo de 2014, relativa a los mercados de instrumentos financieros y por la que se modifican la directiva 2002/92/CE y la directiva 2011/61/UE (DOUE L 173, de 12 de junio de 2014, páginas 349-496).

Directiva (UE) 2019/1937 del Parlamento Europeo y del Consejo, de 23 de octubre de 2019, relativa a la protección de las personas que informen sobre infracciones del derecho de la unión PE/78/2019/REV/1 (DOUE L 305, de 26 de noviembre de 2019, páginas 17-56).

Directiva (UE) 2020/1504 del Parlamento Europeo y del Consejo, de 7 de octubre de 2020, por la que se modifica la directiva 2014/65/UE relativa a los mercados de instrumentos financieros PE/36/2020/INIT (DOUE L 347, de 20 de octubre de 2020, páginas 50-51).

Ley 24/1988, de 28 de julio, del mercado de valores (BOE núm. 181, de 29 de julio de 1988, páginas 23405-23425).

Ley 34/1988, de 11 de noviembre, general de publicidad (BOE núm. 274, de 15 de noviembre de 1988, páginas 32464-32467).

Ley 49/2002, de 23 de diciembre, de régimen fiscal de las entidades sin fines lucrativos y de los incentivos fiscales al mecenazgo (BOE núm. 307, de 24 de diciembre de 2002, páginas 45229-45243).

Ley 17/2009, de 23 de noviembre, sobre el libre acceso a las actividades de servicios y su ejercicio (BOE núm. 283, de 24 de noviembre de 2009, páginas 99570-99593).

Ley $7 / 2010$, de 31 de marzo, general de la comunicación audiovisual (BOE núm. 79, de 1 de abril de 2020, páginas 30157-30209).

Ley 20/2013, de 9 de diciembre, de garantía de la unidad de mercado (BOE núm. 295, de 10 de diciembre de 2013, páginas 97953-97978).

Ley $9 / 2014$, de 29 de diciembre, de impulso de la actividad y del mecenazgo cultural en la Comunitat Valenciana (BOE núm. 35, de 10 de febrero de 2015, páginas 11119-11132).

Ley $3 / 2015$, de 23 de marzo, por la que se regula el consumo cultural y el mecenazgo cultural, científico y de desarrollo tecnológico y se establecen medidas 
tributarias de la Comunidad Autónoma de las Illes Balears (BOE núm. 96, de 22 de abril de 2015, páginas 34948-34961).

Ley 6/2015, de 30 de marzo, por la que se regula el mecenazgo deportivo y se establecen medidas tributarias de la Comunidad Autónoma de Illes Balears (BOE núm. 104, de 1 de mayo de 2015, páginas 38214-38226).

Ley 5/2015, de 27 de abril, de fomento de la financiación empresarial (BOE núm. 101, de 28 de abril de 2015, páginas 36599 a 36684).

Ley 20/2018, de 25 de julio, del mecenazgo cultural, científico y deportivo no profesional en la Comunitat Valenciana (BOE núm. 223, de 14 de septiembre de 2018, páginas 88887-88900).

Ley 9/2019, de 13 de diciembre, de mecenazgo cultural de Castilla-La Mancha (BOE núm. 31, de 5 de febrero de 2020, páginas 10968-10982).

Ley foral 8/2014, de 16 de mayo, reguladora del mecenazgo cultural y de sus incentivos fiscales en la comunidad foral de Navarra (BOE núm. 137, de 6 de junio de 2014, páginas 42982-42997).

Ley orgánica $3 / 2018$, de 5 de diciembre, de protección de datos personales y garantía de los derechos digitales (BOE núm. 294, de 6 de diciembre de 2018, páginas 119788-119857).

Proyecto de ley de fomento de financiación empresarial. Recuperado de http:// www.mineco.gob.es/stfls/mineco/prensa/noticias/2014/proyecto_de_ley_de_fomento_de_la_financiacion_empresarial.pdf [Fecha de consulta: 02/01/2021].

Real decreto 1270/2003, de 10 de octubre, por el que se aprueba el reglamento para la aplicación del régimen fiscal de las entidades sin fines lucrativos y de los incentivos fiscales al mecenazgo (BOE núm. 254, de 23 de octubre de 2003, páginas 27886 a 37893 ).

Real decreto 1804/2008, de 3 de noviembre, por el que se desarrolla la ley 36/2006, de 29 de noviembre, de medidas para la prevención del fraude fiscal, se modifica el reglamento para la aplicación del régimen fiscal de las entidades sin fines lucrativos y de los incentivos fiscales al mecenazgo, aprobado por el real decreto 1270/2003, y se modifican y aprueban otras normas tributarias (BOE núm. 278, de 18 de noviembre de 2008, páginas 45830-45837).

Real decreto legislativo 4/2015, de 23 de octubre, por el que se aprueba el texto refundido de la ley del mercado de valores (BOE núm. 255, de 24 de octubre de 2015, páginas 100356-100541). 
Reglamento (UE) 2016/679 del Parlamento Europeo y del Consejo de 27 de abril de 2016 relativo a la protección de las personas físicas en lo que respecta al tratamiento de datos personales y a la libre circulación de estos datos y por el que se deroga la directiva 95/46/CE (DOUE L 119/1, de 4 de mayo de 2016).

Reglamento (UE) 2017/1129 del Parlamento Europeo y del Consejo, de 14 de junio de 2017, sobre el folleto que debe publicarse en caso de oferta pública o admisión a cotización de valores en un mercado regulado y por el que se deroga la directiva 2003/71/CE (DOUE L 168, de 30 de junio de 2017, páginas 12-82).

Reglamento (UE) 2020/1503 del Parlamento Europeo y del Consejo, de 7 de octubre de 2020, relativo a los proveedores europeos de servicios de financiación participativa para empresas, y por el que se modifican el reglamento (UE) 2017/1129 y la directiva (UE) 2019/1937 (DOUE L 347/1, de 20 de octubre de 2020, páginas 1-49).

Fecha de recepción: 10-01-2021

Fecha de aceptación: 10-08-2021 
